\title{
Publisher Correction: Burma Terrane part of the Trans-Tethyan arc during collision with India according to palaeomagnetic data
}

Jan Westerweel (D), Pierrick Roperch, Alexis Licht (D), Guillaume Dupont-Nivet Di, Zaw Win, Fernando Poblete,

Gilles Ruffet, Hnin Hnin Swe, Myat Kai Thi and Day Wa Aung

Correction to: Nature Geoscience https://doi.org/10.1038/s41561-019-0443-2, published online 9 September 2019.

In the version of this Article originally published the following sentence was mistakenly omitted from the Acknowledgements: 'Finally, we are grateful to C. Morley, R. Hall and J. Geissman for their constructive comments, which helped to clarify our data presentation and model.' This has now been corrected.

Published online: 8 October 2019

https://doi.org/10.1038/s41561-019-0482-8 